INTERNATIONAL HIGHER EDUCATION NO. 69 FALL 2012

\title{
Crisis in the Dutch Universities of Applied Sciences
}

HANS de WIT

Hans de Wit is professor of internationalization of higher education, at the Amsterdam University of Applied Sciences in the Netherlands, and director of the Centre for Higher Education Internationalisation at the Università Cattolica Sacro Cuore in Milan, Italy. E-mail: j.w.m.de.wit@hva.nl.

Universities of applied sciences in the Netherlands are facing severe criticism from media and politicians, about their performance. In 2010, the InHolland University of Applied Sciences, one of the larger universities of applied sciences, was confronted with scandals about bachelor's degrees in media and entertainment management-given to students who were allowed to pass without proper qualifications, as to increase the graduation rate. Also, the governing board was criticized for exorbitant declarations. In 2011, Stenden Hogeschool was criticized for granting bachelor's degrees, in violation of ministerial regulations, at its four international branch campuses. Windesheim Hogeschool was in the same year criticized for the quality of its journalism degrees. At the end of 2011, the Hogeschool van Amsterdam was confronted with accusations about the quality of the degrees of its school of economics and management. These were only some of the main scandals.

The main issues are the quality of the degrees-including accusations of diploma fraud, high dropout rates, and poor graduation rates. This negative 
perception of the current performance of Dutch universities of applied sciences should be understood in the context of reform of Dutch higher education and of the demands of the global knowledge society.

Like other European countries—such as, Austria, Belgium, Germany, and the Scandinavian countries-the Netherlands has a binary system of higher education, composed of research universities and universities of applied sciences. In comparison to the other countries, in the Netherlands the sector of universities of applied sciences is larger in the number of students and institutions than the 13 research universities. Of the 600,000 students in Dutch higher education, over 400,000 study at around 40 universities of applied sciences.

\section{MERGERS AND MASSIFICATION}

Over the past two decades, the universities of applied sciences have gone through a merger process, in which the 400 institutions were reduced by 90 percent. The rationale behind this merger process was based on an increase in the number of students in this sector, instead of an expansion of the research universities, as to maintain the quality of academic education and to reduce its costs. The result has been that big conglomerates have emerged, several of them comprising over 30,000 students.

In the same period, the number of students doubled. Economics and management, 40 years ago a rather small discipline, are responsible for the largest growth (one-third of the total number of students), but all disciplines have faced a substantive increase. 
Universities of applied sciences mainly provide undergraduate education, a four-year bachelor's degree program-leading to a bachelor's degree in business administration, nursing, and other fields. This sector differs from the three-year bachelor's degree program at the research universities-leading to a bachelor of arts or bachelor of science. Although the universities of applied sciences can develop master's degree programs, these must be self-funded and cannot compete with the subsidized and higher quality master's degree programs of the research universities and, as a result, are nearly nonexistent.

Until the 1990s, the reputation of universities of applied sciences remained quite solid. They delivered graduates with an excellent professional training, provided by a teaching staff that was and still is to a large extent recruited from the professional field itself. In particular, in sectors in which there was and is no equivalent in the research universities (arts, nursing, social work, etc.), the programs continue to have a good national and even international reputation.

The merger process, in combination with the rapid increase in the number of students, is observed as the main reason why the sector is currently under pressure. These are certainly relevant factors, and the related increase of a central and middle management layer is an easy target for criticism. But probably more serious is the lack of innovation in the sector, over the past 20 years. The United Kingdom transferred the polytechnics into new universities; and in countries such as Germany, Denmark, and Norway, the universities of applied sciences invested in applied research, master's degree, and even $\mathrm{PhD}$ programs, as well as in increasing the level of their teaching staff. In the Netherlands, the merger process and massification absorbed all energy, leaving little space for innovation. Only 50 percent of the teaching staff in Dutch universities of applied sciences 
have a master's degree and less than 3 percent have a $\mathrm{PhD}$. This is quite different from Germany and Scandinavia, where most if not all teaching staff have a master's degree and the number of PhDs is between 20 and 40 percent. In 2001, it was decided to create professorships (lectoren) in Dutch universities of applied sciences and to develop applied research. However, their role and numbers are relatively small, and they are too isolated from the teaching and learning side to be effective.

\section{The INSUfFiciency OF EDUCATING GoOd Professionals}

The professional field and the national accreditation agency ask increasingly for graduates who are not only good professionals but also more analytical and reflective-in other words, have more academic skills, in order to be able to operate in the global knowledge society. The curriculum and the teaching staff are not equipped for that. At the same time, the diversity in the student background, including an increasing number of second-generation immigrant students, is placing additional pressure on students. Dropout rates and extended durations of study have increased over the years. As a result, the universities of applied sciences face two conflicting pressures from government: to increase the number of graduates and to improve their quality. Also, program managers and teaching staff feel pressure from the university leadership to increase graduation rates, given that funding is based on the number of graduates. The tension between these two demands has resulted in an increasing number of media scandals, in particular claiming that programs have allowed students to graduate without proper qualifications, as to lift up the numbers. 


\section{Tension Between Higher Graduation Rates and Quality}

On the one hand, program managers and teaching staff feel the pressure of letting students pass; on the other hand, they are pressured to pay more attention to academic skills, for which they are not trained. The leadership of universities of applied sciences and government are also under pressure to react to these incidents. Targets have been set for all teaching staff, in 2016, to have a master's degree-an ambitious if not impossible goal, as no time and funding exist to make that happen. Also, plans are underway to include more space in the curriculum for research and methodology, but this requires different types of skills of the teaching staff than is available.

In comparison with the universities of applied sciences in other countries, which earlier and more gradually have adapted to the requirements from the professional field, Dutch universities of applied sciences face a difficult time. It requires more time and funding than the government in the current economic climate can and will invest in modernizing the sector. The danger might be that the distance to research universities and to universities of applied sciences in other countries is increasing rather than decreasing, and this tendency might impact negatively the still strong reputation of several of their programs. The media scandals and accusations of diploma fraud, in most cases not sustained, are not helping; but the sector can also not ignore the serious quality issue, which is difficult to solve-due to years of ignoring to address the changes that the knowledge economy requires. 